\title{
SARS-CoV-2-related chilblains
}

\author{
Malika A. Ladha MD, Elaine C. Dupuis MD
}

Cite as: CMAJ 2020 July 13;192:E804. doi: 10.1503/cmaj.201348

A healthy 16-year-old girl presented with a 2-week history of painful red-violaceous papules to her left third toe, right fifth toe and right index finger (Figure 1). She had no history of exposure to cold or damp and no systemic symptoms, but she lived with an asymptomatic front-line health care worker. We diagnosed chilblains and investigated for systemic causes.

Our investigation for secondary chilblains included a complete blood count, liver studies, and determination of the levels of creatinine, antinuclear antibody, extractable nuclear antigen, double-stranded DNA, anticardiolipin antibody, lupus anticoagulant, anti- $\beta 2$-glycoprotein, complement, coagulation, D-dimer, cryoglobulins, cryofibringens and cold agglutinins, all of which gave results that were negative or within normal limits. A punch biopsy showed superficial and deep dermal lymphocytic inflammation with subepidermal edema. Because chilblains has been associated with severe acute respiratory syndrome coronavirus 2 (SARS-CoV-2) infection, ${ }^{1-3}$ we collected an oropharyngeal swab for polymerase chain reaction testing, which gave a negative result. However, measurement of IgG and IgA antibody levels by enzyme-linked immunosorbent assay (EUROIMMUN) to SARS-CoV-2 gave positive results. We diagnosed SARSCoV-2-related chilblains. We encouraged our patient to self-isolate, avoid cold and damp conditions, and apply a corticosteroid topically to the symptomatic sites. Her lesions resolved over the next 3 weeks.

Chilblains, also known as pernio, refers to a superficial inflammatory cutaneous disease triggered by cool or damp environments. Chilblains is categorized as primary (idiopathic) or secondary to autoimmune, hematologic or autoinflammatory diseases. ${ }^{4}$ As chilblains is often unrecognized, its incidence remains unknown. It more commonly affects women, and idiopathic chilblains is more common in children, whereas secondary chilblains usually presents in mid-adulthood. ${ }^{4}$

Chilblains has been reported as a cutaneous, often late, manifestation of coronavirus disease 2019 (COVID-19) ("COVID toes"). ${ }^{1-3}$ It can be the sole manifestation of SARS-CoV-2 infection. ${ }^{1,2}$ The average reported age in the 2 case series of patients with COVID-19-related chilblains was 14 and 32 years. ${ }^{1,3}$ Because the virus may have cleared by the time of cutaneous presentation, clinicians should consider antibody testing to identify SARS-CoV-2. Although chilblains is considered to be a late manifestation of COVID-19, ${ }^{1}$ more evidence regarding its presentation and the risk of transmission of SARS-CoV-2 is required. As a precaution, all patients with suspected SARS-CoV2-related chilblains should be encouraged to self-isolate.

\section{References}

1. Freeman EE, McMahon DE, Lipoff JB, et al. Pernio-like skin lesions associated with COVID-19: a case series of 318 patients from 8 countries. J Am Acad Dermatol 2020; May 29;S0190-9622(20)30984-1 [Epub ahead of print]. doi: 10.1016/j.jaad.2020.05.109.

2. Galván Casas C, Català A, Carretero Hernández G, et al. Classification of the cutaneous manifestations of COVID-19: a rapid prospective nationwide consensus study in Spain with 375 cases. Br J Dermatol 2020; Apr. 29 [Epub ahead of print]. doi: 10.1111/bjd.19163.

3. Piccolo V, Neri I, Filippeschi C, et al. Chilblain-like lesions during COVID-19 epidemic: a preliminary study on 63 patients. J Eur Acad Dermatol Venereol 2020; Apr. 24 [Epub ahead of print]. doi: 10.1111/jdv.16526.

4. Cappel JA, Wetter DA. Clinical characteristics, etiologic associations, laboratory findings, treatment, and proposal of diagnostic criteria of pernio (chilblains) in a series of 104 patients at Mayo Clinic, 2000 to 2011. Mayo Clin Proc 2014;89:207-15.

Competing interests: Elaine Dupuis has previously served as a consultant for AbbVie; Amgen; Bausch Health, Canada; Sanofi Genzyme; Novartis; and Pfizer, unrelated to and outside of the submitted work. No other competing interests were declared.

This article has been peer reviewed.

The authors have obtained patient consent.

Affiliation: Division of Dermatology, Department of Medicine, University of Calgary, Calgary, Alta.

Acknowledgement: The authors thank Dr. Marvin Fritzler, director of Mitogen Advanced Diagnostics Corporation, for assistance in laboratory testing and interpretation of results.

Correspondence to: Malika Ladha, maladha@ucalgary.ca 